\title{
Образование электронных пар в низкоразмерных системах, обусловленное спин-орбитальной связью и силами изображения
} Махмудиан М.М. ${ }^{1,2}$, Чаплик А.В. ${ }^{1,2}$

${ }^{1}$ ИФП СО РАН, 630090, Новосибирск, пр. Ак. Лаврентьева, 13

${ }^{2}$ Новосибирский государственный университет, 630090, Новосибирск, ул. Пирогова, 2

DOI $10.34077 /$ Semicond2019-208

Показано, что два электрона, находящиеся в квантовой яме вблизи металлического электрода, притягиваются друг к другу за счет спин-орбитального взаимодействия (СОВ) типа Бычкова-Рашба и сил электростатического изображения. При вполне достижимых значениях характеристических параметров системы эффективное притяжение, вызванное СОВ, превалирует над кулоновским отталкиванием, и становится возможным образование биэлектрона. Теория эффекта особенно проста и наглядна для квантовой проволоки. Энергия связи электронной пары существенно увеличивается при приложении затворного напряжения соответствующей полярности.

Физическая картина обсуждаемого эффекта состоит в следующем. Как известно, в 2D электронной системе, асимметричной в направлении своей нормали, существует СОВ типа БычковаРашба линейное по планарному импульсу. Это взаимодействие расщепляет дисперсию свободной частицы на две ветви $E=p^{2} / 2 m \pm \alpha p$, где $p$ - модуль двумерного импульса, $m-$ эффективная масса, $\alpha$ - характерная для данной системы константа СОВ. Величина $\alpha$ зависит от нормальной к плоскости системы компоненты электрического поля $\alpha=A F$, где $A$ не зависит от поля. В МДП - структуре требуемое нарушение центросимметричности обеспечивается присутствием металлического электрода. В системе двух электронов действующее на каждый из них полное нормальное поле $F$ зависит от расстояния между частицами (см. рис.) и увеличивается с уменьшением $\rho$. Нижняя ветвь расщепленного спектра электрона имеет участок отрицательных значений $E$, наиболее глубокое из которых соответствует петле экстремумов: $E_{\min }=-m \alpha^{2} / 2$. Уменьшение $\rho$ приводит к увеличению параметра $\alpha$ и, следовательно, к понижению энергии системы за счет СОВ, тогда как кулоновское отталкивание дает положительный вклад в

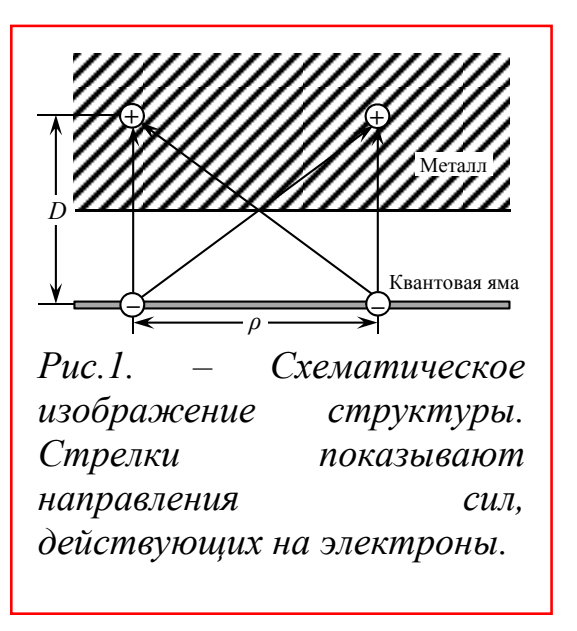
энергию, также растущий при уменьшении $\rho$. Если баланс окажется отрицательным, возникнет связанное состояние - биэлектрон. Очевидно, что соответствующий уровень энергии должен лежать ниже $-m \alpha^{2}-$ суммарной минимальной энергии двух электронов на бесконечно большом расстоянии.

В работе вычислены значения энергии основного уровня электронной пары в МДП-структуре и в квантовой проволоке, расположенной вблизи металлического электрода.

Работа выполнена при финансовой поддержке РФФИ (грант 16-02-00565) и программы РАН (проект 0306 - 2018-0007). 